\title{
An inter-laboratory comparative study of fluoride determination in water
}

\author{
Ji-Hyang Noh and Paul Coetzee* \\ Department of Chemistry, University of Johannesburg, PO Box 524, Auckland Park 2006, South Africa
}

\begin{abstract}
South Africa is on the brink of implementation of mandatory fluoridation of municipal water following the final approval by Parliament in 2001. The ability to accurately measure fluoride in water is an obvious prerequisite for the safe and effective implementation of water fluoridation. This paper evaluates the current status of fluoride determination in water in South Africa. The study was undertaken by the University of Johannesburg in collaboration with the South African Bureau of Standards as part of their ongoing Water-Check Programme. River water, borehole water, and synthetic water samples were sent to 66 participating laboratories in South Africa in March 2004. The results obtained from the analysis of 7 fluoride-containing samples with varying matrix composition, show that $50 \%$ of the laboratories could achieve results that fall between a lower limit of $-20 \%$ and an upper limit of $+20 \%$ relative to the true value. The precision (\%RSD) for the determination of samples with fluoride concentration at the important level below $0.5 \mathrm{mg} / \ell$ was poor, ranging from $\pm 20 \%$ at $0.5 \mathrm{mg} / \ell$ to $\pm 100 \%$ at $0.1 \mathrm{mg} / \ell$. The two major analytical techniques used by the participating South African laboratories were ISE (40\%) and IC $(36 \%)$.
\end{abstract}

Keywords: fluoride determination, inter-laboratory study, water fluoridation

\section{Introduction}

The Department of Health in South Africa has legislated regulations in respect of fluoridation of potable water supplies in September 2000 (Department of Health, 2000). The final regulations were approved by Parliament in September 2001. South Africa is therefore awaiting the implementation of mandatory fluoridation of municipal water up to a level of $0.7 \mathrm{mg} / \ell$. The addition of $\mathrm{F}^{-}$to drinking water up to this level has been approved because of its much publicised beneficial effects on reducing the incidence of dental caries (Underwood, 1977; Murray et al., 1991). The possible negative effects of over-exposure to $\mathrm{F}^{-}$, dental and skeletal fluorosis (Liu, 1995; Chen et al., 1993, 1996; Butler et al., 1985; Richards et al., 1967) are also well known. $\mathrm{F}^{-}$has a relatively narrow range between intake associated with beneficial effects and exposures causing negative effects. As levels of fluoride are increased, the risk of dental fluorosis increases more rapidly than the decrease in dental decay. Because of the small margin of safety between beneficial and toxic levels of $\mathrm{F}^{-}$, the consequences of accidental overdosing could be serious. The ability to accurately measure fluoride concentration in water is therefore an obvious prerequisite for the safe and effective implementation of water fluoridation. In a recent paper (Haarhoff, 2003) it was pointed out that any measurement error, e.g. a modest systematic underestimation of fluoride before and after dosing, will be compounded during the required feedback loop in the dosing procedure resulting in a significant overdose.

The purpose of this study was to evaluate the current status and proficiency of South African laboratories with

* To whom all correspondence should be addressed.

正 +2711489 2558; fax: +27 11489 2819;

e-mail: ppc@,rau.ac.za

Received 24 November 2005; accepted in revised form 15 March 2006. regard to fluoride determination in water. The study was undertaken in collaboration with the South African Bureau of Standards (SABS) as part of their ongoing Water-Check Programme. Water-Check is a high-frequency inter-laboratory proficiency testing programme with the objective of providing a rapid report-back service to participants for self evaluation. A set of $\mathrm{F}^{-}$-containing solutions with different matrix compositions and some containing elements that could interfere with the fluoride determination, was included in the test samples sent out to the participating laboratories. This was done to evaluate the effect of matrix composition and common interferences on routine $\mathrm{F}^{-}$determination in South Africa. A secondary aim was to collect information with regard to the types of analytical technique currently used in South Africa for $\mathrm{F}^{-}$determination and to compare their performance capabilities.

\section{Test samples}

The SABS despatched test samples to 66 participating laboratories on 1 March 2004. The return date for results was set as 31 March 2004. The set of 7 samples used in the fluoride proficiency study contained two unpreserved natural water samples, a river water (Sample 2004/03/1) and a borehole water (Sample 2004/03/2) sample, and 5 synthetic water sample concentrates (Samples 2004/03/4/5/6/7 and 8). The composition of the synthetic samples is given in Table 1 . The synthetic samples were prepared using AR grade chemicals. The sample compositions were designed to assess the effect of Al interference (Sample 2004/03/4)the $\mathrm{F}^{-}$concentration level(Sample 2004/03/4/6/7), and varying matrix composition such as the inclusion of formate ions (Sample 2004/03/6 and 7) on $\mathrm{F}^{-}$determination.

Samples for analyses were prepared by pipetting $20 \mathrm{~m} \ell$ of the concentrate solutions into $500 \mathrm{~m} \ell$ volumetric flasks and diluting to volume with deionised water. 


\begin{tabular}{|l|c|c|c|c|c|}
\hline \multicolumn{6}{|c|}{$\begin{array}{c}\text { TABLE 1 } \\
\text { Composition } \\
\text { of the synthetic samples } \\
\text { ing }\end{array}$} \\
\hline \multirow{2}{*}{ Species } & \multicolumn{5}{|c|}{ Sample number 2004/03/.. } \\
\cline { 2 - 6 } & $\mathbf{4}$ & $\mathbf{5}$ & $\mathbf{6}$ & $\mathbf{7}$ & $\mathbf{8}$ \\
\hline $\mathrm{Na}^{+}$ & & & & & \\
\hline $\mathrm{Ca}^{2+}$ & - & 0.8 & 0.8 & 0.8 & - \\
\hline $\mathrm{Mg}^{2+}$ & - & 0.8 & 0.8 & 0.8 & - \\
\hline $\mathrm{Al}^{3+}$ & 1 & - & - & - & - \\
\hline $\mathrm{F}^{-}$ & 0.25 & 0.10 & 0.54 & 1.50 & 0.90 \\
\hline $\mathrm{Formate}^{3+}$ & - & - & 4 & 4 & - \\
\hline $\mathrm{Cl}^{-}$ & 18.77 & 27.23 & 22.66 & 32.90 & 24.61 \\
\hline $\mathrm{NO}_{3}{ }^{-}$ & - & 4 & 4 & 4 & - \\
\hline $\mathrm{PO}_{4}{ }^{3-}$ & - & 4 & 4 & 4 & - \\
\hline $\mathrm{SO}_{4}{ }^{2-}$ & 13.77 & 20.09 & 24.47 & 32.00 & 40.86 \\
\hline
\end{tabular}

\section{Results and discussion}

\section{Statistical evaluation of results}

The Water-Check Programme makes use of robust statistics, applying down-weighting of outlying data without excluding such data for data evaluation. For this study, all the original values, outliers included, were recaptured electronically in the reporting process adopted by the SABS. The Z-score for each result is calculated and an average $Z$-score then calculated for each laboratory. The Z-scores are calculated as follows:

$$
\begin{aligned}
& \text { Z-score }=\frac{x-\bar{x}}{s}, \bar{x}=\text { robust mean (median) in case of natural } \\
& \text { samples } \\
& \text { Z-score }=\frac{x-t}{s}, t=\text { true value in case of synthetic samples }
\end{aligned}
$$
or

The $\mathrm{F}^{-}$data consisted of $446 \mathrm{~F}^{-}$values obtained from the 66 participating laboratories of which 44 returned method information sheets. The statistical summary of the results is presented in Table 2. True values were not available for the natural water samples, river water (Sample 1) and borehole water (Sample 2).

In the synthetic samples the medians were relatively close to the true values, $\mathrm{F}^{-}$was under-estimated in Samples 4, 6 and 7 by $-12.0 \%,-7.4 \%$ and $-5.3 \%$, respectively, and over-estimated by $1.1 \%$ in Sample 8 and by $30.0 \%$ in Sample 5. In the latter case the $\mathrm{F}^{-}$concentration of $0.1 \mathrm{mg} / \ell$ in the sample is very low and close to the limit of quantitative determination for the techniques used in this study. Because of the low concentration even a small measurement uncertainty of $0.01 \mathrm{mg} / \ell$ for example, will result in a large relative error of $10 \%$. The standard deviations vary between $30 \%$ and $77 \%$ for $\mathrm{F}^{-}$concentrations below $0.5 \mathrm{mg} / \ell$. This large spread in results emphasises the difficulty in determining $\mathrm{F}^{-}$at the (for fluoridation) critically important concentration levels below $0.5 \mathrm{mg} / \ell$. As could be expected the SDs improve substantially with increasing $\mathrm{F}^{-}$concentration above $0.5 \mathrm{mg} / \ell$. The complication introduced when $\mathrm{Al}$ is present, is reflected in the relatively high SD for Sample 4. Al forms complexes with $\mathrm{F}^{-}$such as $\mathrm{AlF}^{2+}$ and $\mathrm{AlF}_{2}^{+}$thus rendering $\mathrm{F}^{-}$analytically inaccessible as $\mathrm{F}^{-}$, resulting in an under-estimation of the free $\mathrm{F}^{-}$concentration. The problem can be resolved by adding a decomplexing agent such as CDTA (trans-1, 2-cyclohexylenedinitrilo) tetra-acetic acid. In using
TABLE 2

Statistical summary of $446 \mathrm{~F}^{-}$results obtained from 66 laboratories

\begin{tabular}{|c|c|c|c|c|c|c|}
\hline $\begin{array}{c}\text { Sample } \\
\text { number }\end{array}$ & $\begin{array}{c}\text { True } \\
\mathbf{m g} / \boldsymbol{l}\end{array}$ & Median & \% Error & $\begin{array}{c}\text { Robust } \\
\text { SD }\end{array}$ & \%RSD & N \\
\hline 1 & - & 0.16 & - & 0.07 & 44 & 62 \\
\hline 2 & - & 0.20 & - & 0.06 & 30 & 63 \\
\hline 4 & 0.25 & 0.22 & -12.0 & 0.12 & 55 & 61 \\
\hline 5 & 0.10 & 0.13 & +30.0 & 0.10 & 77 & 63 \\
\hline 6 & 0.54 & 0.50 & -7.4 & 0.10 & 20 & 66 \\
\hline 7 & 1.50 & 1.42 & -5.3 & 0.19 & 13 & 66 \\
\hline 8 & 0.90 & 0.91 & +.1 .1 & 0.10 & 11 & 65 \\
\hline
\end{tabular}

ISEs (ion selective electrodes) a decomplexing agent is usually part of the TISAB (total ionic strength adjustment buffer) solution recommended for $\mathrm{F}^{-}$determination. The effectiveness of this procedure strongly depends on the type and condition of the TISAB solution used.

Formate, an organic acid anion that might be present in natural water samples, gives a retention time of close to $\mathrm{F}^{-}$in the ion chromatographic determination of $\mathrm{F}^{-}$and could result in the chromatographic peaks overlapping. The relatively small negative error shown for Samples 6 and 7 seems to indicate, however, that the formate interference is negligible at the concentration levels of $\mathrm{F}^{-}$and formate in these samples.

In natural water samples there are many unknown dissolved and suspended components that could affect the $\mathrm{F}^{-}$measurements. It is therefore to be expected that SDs will be high at the low $\mathrm{F}^{-}$concentrations in these samples.

\section{Comparison of analytical methods}

Data from the method information sheets, returned by 44 out of 66 laboratories, were analysed to compare the correlation between accuracy and analytical method. The methods used by the different laboratories are listed in Table 3.

The Z-score is a useful indication of the accuracy of a measurement. Absolute Z-scores are graphically shown in Fig. 1. The $Z$-score expresses the deviation of a measurement from the median or true value relative to the standard deviation. A smaller Z-score indicates a better accuracy. The overall average absolute Z-scores for ISE, the spectrophotometric SPANDS (2-(para-sulphophenylazo)-1, 8-dihdroxynaphthalene-3, 6-disulphonate) method, and IC (ion chromatography)

\begin{tabular}{|c|c|c|}
\hline \multicolumn{3}{|c|}{$\begin{array}{c}\text { TABLE } 3 \\
\begin{array}{c}\text { Analytical methods for F- determination } \\
\text { in this study }\end{array}\end{array}$} \\
\hline Analytical methods & $\begin{array}{c}\text { Number of } \\
\text { laboratories }\end{array}$ & $\%$ \\
\hline ISE & 18 & 40 \\
\hline IC & 16 & 36 \\
\hline SPANDS & 8 & 18 \\
\hline Others & 3 & 6 \\
\hline Total numbers & 45 & 100 \\
\hline
\end{tabular}
are $0.98,1.25$, and 1.33 respectively. 
Figure 1

Average absolute Z-score for $446 F^{-}$measurements from 66 laboratories

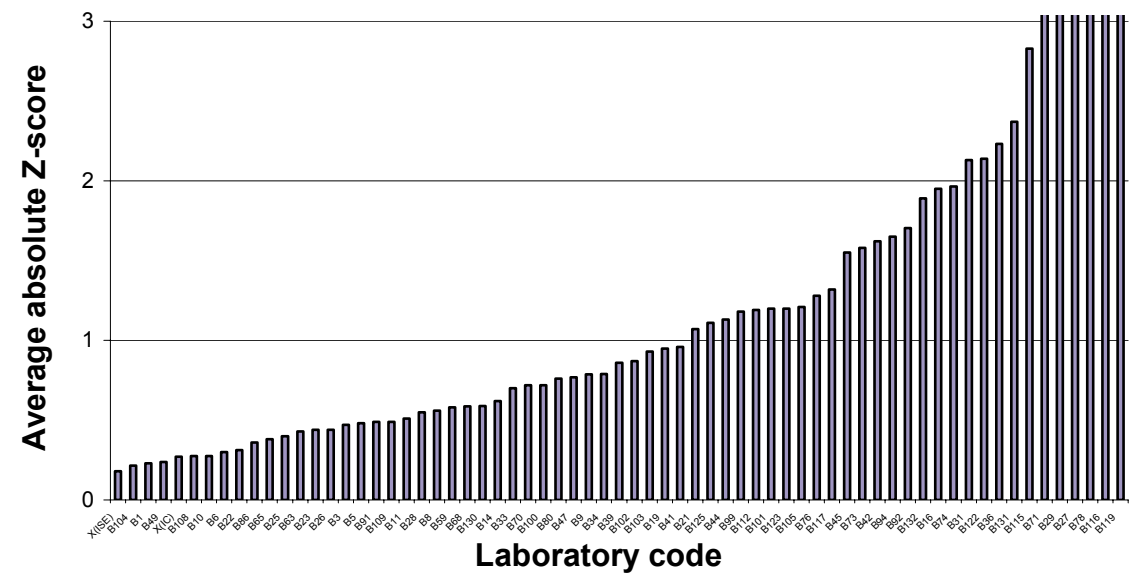

Lab X, the Analytical Chemistry Research Laboratory at the University of Johannesburg, shows the lowest Z-score in this inter-laboratory study. The good performance of this laboratory is the result of applying a set of precautions and diligently avoiding pitfalls associated with the determination of fluoride using ISEs and IC. The study of pitfalls in ISE and IC determination of fluoride conducted in this laboratory is reported elsewhere (Noh, 2005).

The performance of the analytical laboratories in South Africa, participating in this proficiency testing exercise for the measurement of $\mathrm{F}^{-}$, is summarised in Table $4.56 \%$ of laboratories in this study reported results that fall within the $\mathrm{Z}<1$ category.

Table 4 gives a general evaluation of laboratory performance in terms of Z-score. The more strict requirements applicable to the fluoridation environment, however, demand that we look more carefully at the above assessment. If the standard deviations given in Table 2 are taken into consideration, the $\mathrm{Z}<1$ limit could hardly be considered good in cases where the $\%$ RSD $>20 \%$ as is the case for Samples 1, 2, 4, 5, and 6. It can, for example be shown that an under-estimation of $20 \%$ will lead to overdosing of nearly $30 \%$ in a typical fluoridation application (Haarhoff, 2004).

\begin{tabular}{|l|c|c|c|}
\hline \multicolumn{4}{|c|}{ TABLE 4 } \\
\hline Laboratory performance \\
\hline $\mathrm{Z}$-score & Status & $\begin{array}{c}\text { Numbers of } \\
\text { laboratories }\end{array}$ & $\%$ \\
\hline $\mathrm{Z}<1$ & Good & 37 & 56 \\
\hline $1<\mathrm{Z}<2$ & Average & 18 & 27 \\
\hline $\mathrm{Z}>3$ & Unsatisfactory & 11 & 17 \\
\hline Total & 66 & 100 \\
\hline
\end{tabular}

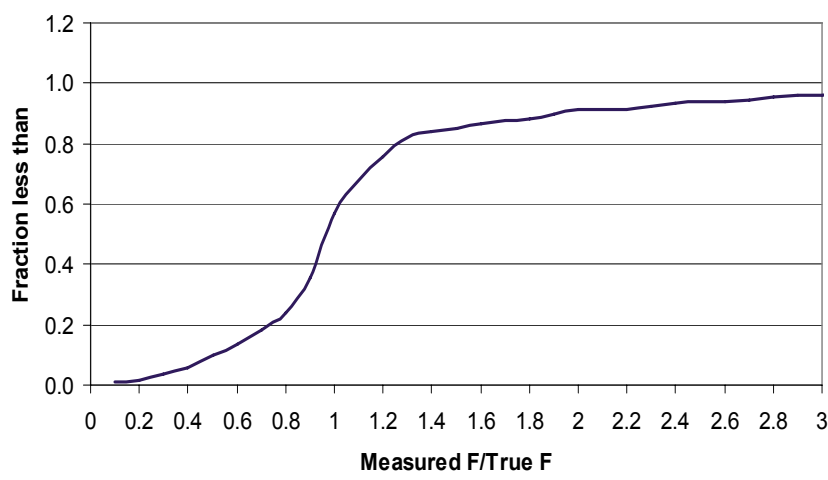

Figure 2

Cumulative distribution plot of 446 fluoride measurements by 66 laboratories
An alternative way of evaluating laboratory performance is to use the cumulative distribution plot of all the measurement data shown in Fig. 2 to provide an estimate of measurement error. If $\pm 20 \%$ is arbitrarily chosen as the maximum allowable error (equivalent to a lower limit and upper limit at an ordinate value of 0.8 and 1.2, respectively in Fig. 2) for $\mathrm{F}^{-}$determination in fluoridation applications, only $50 \%$ of the participating laboratories produced reasonably good results.

In Fig. 3, a cumulative distribution plot for each method shows that $63 \%$ of the $\mathrm{F}^{-}$measurements made by ISE, fall within the $\pm 20 \%$ limits, while for the SPADNS method $52 \%$, and for IC only $39 \%$ fall within the \pm 20 limits.

Cumulative distribution plots for each sample shown in Fig. 4 reveal that for Sample 1, containing $0.1 \mathrm{mg} / \ell \mathrm{F}^{-}$, only $30 \%$

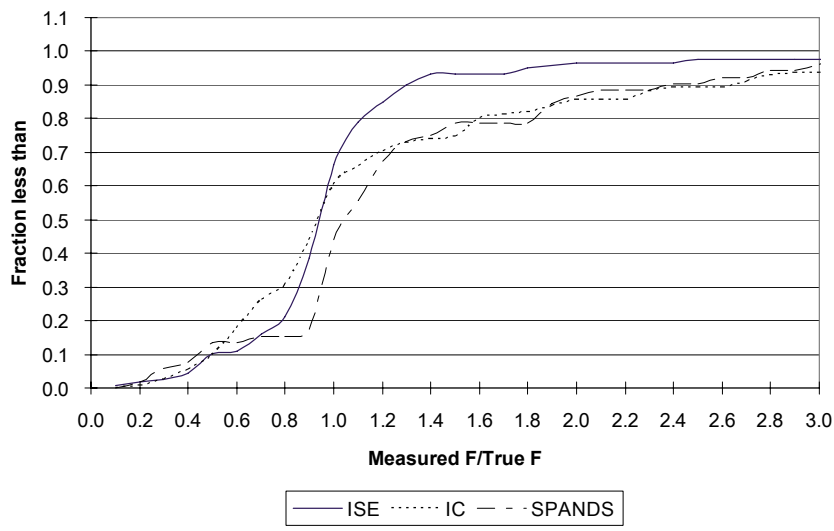

Figure 3

Cumulative distribution plot of $F^{-}$measurement results for each method

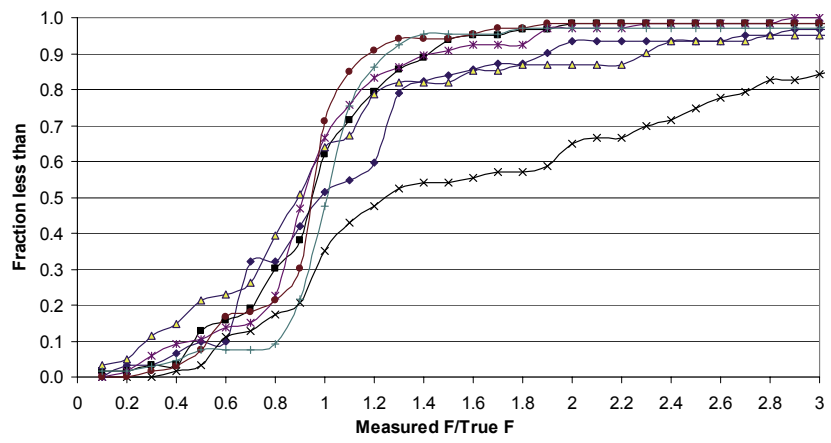

- sample $1-$ sample $2-\triangle$-sample $4 *$ sample $5 \multimap$ sample $6 \rightarrow$ sample $7 \multimap$ sample 8

Figure 4

Cumulative plots of $F^{-}$measurements for each sample 


\begin{tabular}{|l|c|c|}
\hline \multicolumn{3}{|c|}{ TABLE $\mathbf{5}$} \\
\multicolumn{3}{|c|}{$\begin{array}{c}\text { Percentage of measurements falling within } \mathbf{\pm 2 0 \%} \\
\text { limits for each sample }\end{array}$} \\
\hline Sample & $\begin{array}{c}\text { Cumulative } \\
\text { fraction } \\
\text { interval at } \\
\mathbf{\pm 2 0 \%}\end{array}$ & $\begin{array}{c}\text { \% of measure- } \\
\text { ments falling } \\
\text { within } \mathbf{\pm 2 0 \%} \\
\text { limit }\end{array}$ \\
\hline 1: river water & $0.32-0.60$ & 28 \\
\hline 2: borehole water & $0.30-0.79$ & 49 \\
\hline 4: $0.25 \mathrm{mg} / \ell \mathrm{F}^{-} \mathrm{Al}$ interference & $0.39-0.78$ & 39 \\
\hline 5: $0.1 \mathrm{mg} / \ell \mathrm{F}^{-}$ & $0.18-0.48$ & 30 \\
\hline 6: $0.54 \mathrm{mg} / \ell \mathrm{F}^{-}$plus formate & $0.23-0.84$ & 61 \\
\hline 7: $1.50 \mathrm{mg} / \ell \mathrm{F}^{-}$plus formate & $0.22-0.91$ & 69 \\
\hline 8: $0.90 \mathrm{mg} / \ell \mathrm{F}^{-}$ & $0.09-0.86$ & 77 \\
\hline
\end{tabular}

\begin{tabular}{|l|c|}
\hline \multicolumn{2}{|c|}{ TABLE 6 } \\
ICP-OES operational conditions \\
\hline Parameter & Setting \\
\hline Viewing height & $6 \mathrm{~mm}$ \\
\hline Search window & $0.04 \mathrm{~nm}$ \\
\hline Generator power & $1.20 \mathrm{~kW}$ \\
\hline Plasma gas flow rate & $15.0 \mathrm{l} / \mathrm{min}$ \\
\hline Auxiliary gas flow rate & $1.50 \mathrm{l} / \mathrm{min}$ \\
\hline Pump speed & $25.0 \mathrm{r} / \mathrm{min}$ \\
\hline
\end{tabular}

of the measurements fall within the $\pm 20 \%$ limits. The degree of difficulty in reliably analysing low-level $\mathrm{F}^{-}$is once again emphasised. The performance of the laboratories on a per sample basis is summarised in Table 5.

The complexity of a natural water matrix, in particular river water, and the effect it has on the reliability of $\mathrm{F}^{-}$measurements are reflected in the fact that only $28 \%$ of the measurements for the river water sample fall within the $\pm 20 \%$ limit. This is a serious cause for concern given the fact that water matrices similar to this one would be encountered during the fluoridation process. It is also clear that the presence of $\mathrm{Al}$, a common interferent, can compromise the result when adequate precautions are not taken.

\section{Determination of composition of natural water samples}

The natural water samples were analysed by ICP-OES (inductively coupled plasma- optical emission spectrometry) and IC at the University of Johannesburg to determine whether any elements present in the samples could have sufficiently high concentrations to constitute an interference risk.

A Varian Liberty 100 ICP-OES spectrometer was used for the determination of the elements: $\mathrm{Li}, \mathrm{B}, \mathrm{Na}, \mathrm{Mg}, \mathrm{Al}, \mathrm{Ca}, \mathrm{Cr}$, $\mathrm{Mn}, \mathrm{Fe}, \mathrm{Co}, \mathrm{Ni}, \mathrm{Cu}, \mathrm{Zn}, \mathrm{Sr}, \mathrm{Ba}, \mathrm{Cd}, \mathrm{Pb}$ and Bi. A $1000 \mathrm{mg} / \ell$ Multi IV (Merck SA) multi-element ICP-OES standard was used to prepare calibration standards by appropriate dilution with $2 \%$ $\mathrm{HNO}_{3}$. The experimental conditions used in ICP-OES measurements are summarised in Table 6.

A Dionex DX-120 ion chromatographic system, equipped with a Dionex anion exchange column system (AG 14A+AS14A), was used for the determination of the anions: $\mathrm{F}^{-}$, formate, $\mathrm{Cl}^{-}$, $\mathrm{Br}, \mathrm{NO}_{3}^{-}, \mathrm{NO}_{2}^{-}, \mathrm{PO}_{4}^{3-}, \mathrm{SO}_{4}{ }^{2-}$ in the natural samples. The standard $\mathrm{HCO}_{3}-\mathrm{CO}_{3}^{2-}\left(1.0 \mathrm{mM} \mathrm{HCO}_{3}^{-}+3.5 \mathrm{mM} \mathrm{CO}_{3}^{2-}\right)$ eluant, recommended for anion determinations with this column, was used in all determinations.

The results are summarised in Table 7 for those species in Samples 1 and 2 where the concentrations were more than the method detection limit (MDL).

\begin{tabular}{|c|c|c|c|c|}
\hline \multicolumn{5}{|c|}{$\begin{array}{c}\text { TABLE } 7 \\
\text { Composition of the natural samples }(\mathrm{mg} / \mathrm{\ell})\end{array}$} \\
\hline \multicolumn{5}{|c|}{ Composition of the natural samples } \\
\hline Types & Elements & $\begin{array}{l}\text { Detection } \\
\text { limit }\end{array}$ & Sample 1 & Sample 2 \\
\hline \multirow{6}{*}{$\begin{array}{l}\text { Cations } \\
(\mathrm{mg} / \ell)\end{array}$} & $\mathrm{Ca}^{2+}$ & 0.0003 & 36.87 & 70.83 \\
\hline & $\mathrm{Mg}^{2+}$ & 0.0010 & 20.07 & 45.03 \\
\hline & $\mathrm{Sr}^{2+}$ & 0.0002 & 0.038 & 0.13 \\
\hline & $\mathrm{Na}^{+}$ & 0.0100 & 8.52 & 11.15 \\
\hline & $\mathrm{Cu}^{2+}$ & 0.0200 & $<\mathrm{DL}$ & 0.020 \\
\hline & $\mathrm{Al}^{3+}$ & 0.0150 & 0.059 & 0.15 \\
\hline \multirow{3}{*}{$\begin{array}{l}\text { Anions } \\
(\mathrm{mg} / \ell)\end{array}$} & $\mathrm{Cl}^{-}$ & - & 6.27 & 20.77 \\
\hline & $\mathrm{NO}_{3}^{-}$ & - & 3.39 & 26.41 \\
\hline & $\mathrm{SO}_{4}^{2-}$ & - & 12.43 & 29.11 \\
\hline
\end{tabular}

The results show relatively low levels of $\mathrm{Al}$, an element known to interfere in the ISE determination of F. At this level the TISAB solutions normally used for $\mathrm{F}^{-}$determination (TISAB III) would adequately resolve the reduction in $\mathrm{F}^{-}$signal caused by the presence of Al. The reason for the high\%RSDs could therefore be ascribed to the relatively low $\mathrm{F}^{-}$concentrations in the samples and to the matrix effects.

\section{Determination of Laboratory Fortified Matrix (LFM) samples}

A useful procedure to assess whether a method is prone to matrix effects is the Laboratory Fortified Matrix (LFM) Method, which is a quality control procedure used in the EPA approved method for $\mathrm{F}^{-}$determination (Daniel, 1997). The LFM sample is an aliquot of an environmental sample to which known quantities of the method analytes are added. The LFM is analysed exactly like a sample, and its purpose is to determine whether the sample matrix contributes bias to the analytical results. The background concentrations of the analytes in the sample matrix must be determined in a separate aliquot and the measured values in the LFM corrected for background concentrations. The LFM should be prepared at concentrations no greater than five times the highest concentration observed in any field sample.

Per cent recovery is calculated using the following equation:

$$
\begin{aligned}
\text { tion: } & C_{s}-C \\
\text { where: } & \text { S } \\
R & =\% 100 \\
C S & =\text { fortified sample concentration } \\
C & =\text { sample background concentration } \\
S & =\text { concentration equivalent of analyte added to sample }
\end{aligned}
$$

The satisfactory recovery limits range between 75 and $125 \%$. If the recovery of any analyte falls outside the designated LFM recovery range, the recovery problem encountered with the LFM is judged to be matrix induced and the results for that sample and the LFM are reported with a "matrix induced bias" qualifier.

To check the possible effect of the matrix on the determination of $\mathrm{F}^{-}$in the Water-Check samples, the samples were spiked with known amounts of $\mathrm{F}^{-}$, to prepare a set of LFM check samples. The recoveries obtained in the analysis of these samples are given in Table 8.

The results, except Sample 1 using ISE, displayed acceptable recoveries ( 75 to $125 \%$, US EPA method 300.1 ) for $\mathrm{F}^{-}$in all 


\begin{tabular}{|l|c|c|c|c|c|c|c|c|c|}
\hline \multicolumn{7}{|c|}{ \%ABLE 8 } \\
\hline \multicolumn{7}{|c|}{ Inalytical method } \\
\hline & \multicolumn{8}{|c|}{ Ion selective electrode } & \multicolumn{7}{c|}{ lon chromatography } \\
\hline Sample number & Fortified & Sample & Spike & $\begin{array}{c}\text { Recovery } \\
\%\end{array}$ & $\begin{array}{c}\text { Sample } \\
\text { number }\end{array}$ & Fortified & Sample & $\begin{array}{c}\text { Spike } \\
\text { Recovery } \\
\%\end{array}$ \\
\hline Unfiltered \#1 & 0.607 & 0.141 & 0.3 & 155.0 & - & - & - & - & - \\
\hline Unfiltered after 24 h \#1 & 1.033 & 0.138 & 0.3 & 298.3 & - & - & - & - & - \\
\hline Filtered \#1 & 0.412 & 0.140 & 0.3 & 90.7 & $\# 1$ & 0.445 & 0.152 & 0.3 & 97.7 \\
\hline Filtered UV \#1 & 0.415 & 0.141 & 0.3 & 91.3 & - & - & - & - & - \\
\hline$\# 2$ & 0.566 & 0.189 & 0.4 & 94.2 & $\# 2$ & 0.557 & 0.169 & 0.4 & 97.0 \\
\hline$\# 4$ & 0.576 & 0.232 & 0.4 & 86.2 & $\# 4$ & 0.656 & 0.246 & 0.4 & 102.5 \\
\hline$\# 5$ & 0.288 & 0.103 & 0.2 & 92.4 & $\# 5$ & 0.292 & 0.109 & 0.2 & 91.6 \\
\hline$\# 6$ & 1.472 & 0.487 & 1 & 98.5 & $\# 6$ & 1.437 & 0.474 & 1 & 96.3 \\
\hline$\# 7$ & 4.476 & 1.450 & 3 & 100.9 & $\# 7$ & 4.422 & 1.391 & 3 & 101.0 \\
\hline$\# 8$ & 2.879 & 0.879 & 2 & 100.0 & $\# 8$ & 2.874 & 0.849 & 2 & 101.3 \\
\hline
\end{tabular}

matrices. This indicates that the analytical methods, ISE and IC, are both acceptable methods to measure $\mathrm{F}^{-}$in water samples.

The initial\% recovery of Sample 1 (river water) was $155.0 \%$, which was out of the reasonable recovery range (75 to $125 \%$ ). Therefore Sample 1 was further analysed with ISE using three different methods. In the first, the sample was measured $24 \mathrm{~h}$ after fortification, in the second, the sample was filtered first and then measured after fortification, while in the third, the sample was measured after fortification, filtration and UV treatment. The filtration was chosen with the expectation that removal of any unknown factors that could affect the $\mathrm{F}^{-}$determination in the natural samples, would improve the accuracy. UV lamp exposure was tested with the expectation of breaking up the organic material in natural samples. The recoveries improved to $90.7 \%$ and $91.3 \%$, respectively, after filtration and filtration with UV lamp exposure. However, the result $24 \mathrm{~h}$ after fortification was the least impressive, $298 \%$, and was in fact worse than before. This indicated that filtration was necessary in natural river water samples for accurate $\mathrm{F}^{-}$measurement, although not the case in the synthetic samples with ISE. Sample 2 (borehole water), another natural sample, showed a reasonable LFM recovery value, even without filtration. It is therefore clear that the matrix could affect the analytical results for $\mathrm{F}^{-}$determination, even though the analytical method was accurate enough. When the ion composition of these samples was compared (Table 6), Sample 2 contained a larger concentration of each element. Even though a lower concentration of ions occurred in the river water sample, the LFM recovery value was out of the acceptable recovery range. This means that there were other factors that caused the erroneous LFM value in the river water sample. This problem could be solved by filtration.

In the case of synthetic samples, the recovery for Sample 4, which contained Al interference, was lower, $86.2 \%$, for ISE determination than for the other samples. This occurred because of the formation of Al-F complexes and the less than $100 \%$ efficiency of the decomplexing agent to break up the complex. In the case of IC the recovery of Sample 4 was $102.5 \%$. This means that $\mathrm{Al}$ at this level is not problematic in the determination of $\mathrm{F}^{-}$, using IC in terms of interference, but the precipitation of $\mathrm{Al}$ hydroxide in basic medium should be considered, since precipitation could damage the column.

The recoveries for Sample 5 were lower for both methods (92.4\% and $91.6 \%$ ), because of a very low level of $\mathrm{F}^{-}$at $0.10 \mathrm{mg} / \ell$. The other synthetic Samples, 6, 7 and 8, yielded good results, close to $100 \%$ recovery. These samples did not display any significant interference that could result in serious error.

\section{Conclusion}

$\mathrm{F}^{-}$measurement by ISE is the predominant method used by the 66 participating laboratories to determine fluoride in water samples. Results obtained by this method produced the best average Z-scores. $50 \%$ of the measurements obtained from all the methods and all 66 laboratories fall between an arbitrarily set lower limit of $-20 \%$ and an upper limit of $+20 \%$ with respect to the median or true value. It can be shown that an under-estimation of $20 \%$ could lead to an overdose of almost $30 \%$ in a typical fluoridation application. Obviously the accuracy limits achieved by the best $50 \%$ of the laboratories are hardly adequate for ensuring reliable and accurate dosage in a fluoridation programme. The results have shown that by taking the necessary precautions and avoiding the numerous pitfalls in fluoride determinations very accurate results are indeed attainable.

\section{Acknowledgement}

The SABS (Mr Chris Fouché) is thanked for the preparation and shipment of fluoride- containing samples to participating laboratories in the Water-Check Programme and for sharing relevant data.

\section{References}

BUTLER WJ, SEGRETO V and COLLINS E (1985) Prevalence of dental mottling in school-aged lifetime residents of 16 Texas communities. Am. J. Public Health 75 1408-1412.

CHEN XY, LIN MQ, HE ZL, CHEN C, MIN D, LIU YQ and YU MH (1996) Relationship between total fluoride intake and dental fluorosis in areas polluted by airborne fluoride. Fluoride 29 7-12.

CHEN Y, LIN M, HE Z, XIE X, LIU Y, XIAO Y, ZHOU J, FAN U, XIAO Z and XU F (1993) Air pollution-type fluorosis in the region of Pingxiang, Jiangxi, People's Republic of China. Arch. Environ. Health 48 246-249.

DANIEL PH (1997) US EPA Method 300.1 (1997) Determination of Inorganic Anions in Water by Ion Chromatography. Revision 1.0. US Environmental Protection Agency, Cincinnati, OH 45268.

DEPARTMENT OF HEALTH (2000) Regulation No. 873 Regulations under the Health Act, 1977 (Act No. 63 of 1977) Regulations on Fluoridating Water Supplies. Government Gazette No. 21533 (Vol. 423) 8 Sep (Regulation Gazette No. 6874). Pretoria, South Africa. 
HAARHOFF J (2003) The accuracy of fluoride measurement in water and its implications for water fluoridation. Water SA 29 219-224.

LIU Y (ed.) (1995) Human Exposure Assessment of Fluoride. An international study within the WHO/UNEP Human Exposure Assessment Location (HEAL) Programme. Beijing, Chinese Academy of Preventive Medicine, Institute of Environmental HealthMonitoring, Technical Cooperation Centre of Fluoride/ HEAL Programme. 64 pp.

MURRAY JJ, RUGGOGUNN AJ and JENKINS GN (1991) Fluorides in Caries Prevention ( $3^{\text {rd }}$ edn.). Butterworth-Heineman Ltd., Oxford.
NOH J-H (2005) Evaluation of Analytical Methodologies for Fluoride Determination and Speciation of Fluoro Complexes of Aluminium. Unpublished M.Sc. Thesis, University of Johannesburg.

RICHARDS LF, WESTMORELAND WW, TASHIRO M, McKAY CM and MORRISON TJ (1967) Determination of optimum fluoride levels for community water supplies in relation to temperature. J. Am. Dent. Assoc. 74 389-397.

UNDERWOOD EJ (1977) Trace Elements in Human and Animal Nutrition $\left(4^{\text {th }}\right.$ edn.) Academic Press, New York, San Francisco, London. 